\title{
Study of a Triazole Derivative as Corrosion Inhibitor for Mild Steel in Phosphoric Acid Solution
}

\author{
Lin Wang, Ming-Jie Zhu, Fa-Chang Yang, and Cheng-Wei Gao \\ School of Chemical Science and Technology, Yunnan University, Kunming, Yunnan 650091, China \\ Correspondence should be addressed to Lin Wang, wanglin@ynu.edu.cn
}

Received 14 July 2011; Accepted 16 November 2011

Academic Editor: Omar S. Es-Said

Copyright () 2012 Lin Wang et al. This is an open access article distributed under the Creative Commons Attribution License, which permits unrestricted use, distribution, and reproduction in any medium, provided the original work is properly cited.

The corrosion inhibition by a triazole derivative (PAMT) on mild steel in phosphoric acid $\left(\mathrm{H}_{3} \mathrm{PO}_{4}\right)$ solution has been investigated by weight loss and polarization methods. The experimental results reveal that the compound has a significant inhibiting effect on the corrosion of steel in $\mathrm{H}_{3} \mathrm{PO}_{4}$ solution. It also shows good corrosion inhibition at higher concentration of $\mathrm{H}_{3} \mathrm{PO}_{4}$. Potentiodynamic polarization studies have shown that the compound acts as a mixed-type inhibitor retarding the anodic and cathodic corrosion reactions with predominant effect on the cathodic reaction. The values of inhibition efficiency obtained from weight loss and polarization measurements are in good agreement. The adsorption of this compound is found to obey the Langmuir adsorption isotherm. Some kinetic and thermodynamic parameters such as apparent activation energy, frequency factor, and adsorption free energy have been calculated and discussed.

\section{Introduction}

The use of inhibitors is one of the most practical methods for protection of metal against corrosion, especially in acidic media [1]. Most of the well-known acid inhibitors are organic compounds containing nitrogen, sulphur, and oxygen atoms. Compounds with $\pi$-electrons and functional groups containing heteroatoms which can donate lone pair electrons are found to be particularly useful as inhibitors for corrosion of metals [2-5]. The exiting data reveal that most organic inhibitors act by adsorption on the metal surface. This adsorption is influenced by the nature and surface charge of metal, the type of aggressive electrolyte and the chemical structure of inhibitors [6]. The compounds containing both nitrogen and sulphur can give excellent inhibition in contrast to compounds containing only nitrogen or sulphur [7]. Triazole and triazole-type compounds containing nitrogen, sulphur, and heterocycle on the corrosion inhibition of metal in acidic media have attracted more attention because of their excellent corrosion inhibition performance [8-11]. The some new triazole derivatives have been still continuously synthesized and investigated as inhibitors for corrosion of metals in acidic solutions [12-14]. For example, Zhang et al. studied the corrosion inhibition of a newly synthesized oxadiazol-triazole derivative for mild steel in sulphuric solution, their results indicated that the compound was effective corrosion inhibitor for mild steel in acid solution and its efficiency attained more than $97.6 \%$ at $298 \mathrm{~K}$ [15]. The researches by Fouda and Ellithy showed that some 4-phenylthiazole derivatives could inhibit the corrosion of $304 \mathrm{~L}$ stainless steel in hydrochloric acid solution, but the inhibition effect was not very excellent [16]. However, Synergistic effect occurred on addition of KSCN to acid containing 4-phenylthiazole derivatives which inhibited 304L stainless steel corrosion, and the phenomenon of synergism took place at very low concentrations for the systems studied. Wang et al. also investigated the effect of some mercapto-triazole derivatives synthesized containing different hetero atoms and substituents in the organic structures on the corrosion and hydrogen permeation of mild steel in hydrochloric acid solution and their results revealed that all the mercapto-triazole derivatives performed excellently as corrosion inhibitors [17]. Especially, some N- and Scontaining triazole derivatives are environmentally friendly corrosion inhibitors compared with some commercial acid corrosion inhibitors which are highly toxic, such as chromate and nitrite [18].

Although phosphoric acid $\left(\mathrm{H}_{3} \mathrm{PO}_{4}\right)$ is a medium-strong acid, it still shows strong corrosiveness on ferrous or ferrous 


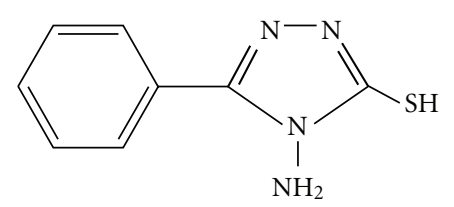

Figure 1: Structure of 3-phenyl-4-amino-5-mercapto-1,2,4-triazole.

TABLE 1

\begin{tabular}{lccccc}
\hline $\mathrm{C}$ & $\mathrm{S}$ & $\mathrm{P}$ & $\mathrm{Mn}$ & $\mathrm{Si}$ & $\mathrm{Fe}$ \\
\hline 0.05 & 0.017 & 0.016 & 0.28 & 0.02 & Balance \\
\hline
\end{tabular}

alloy $[19,20]$. Little work appears to have been done on the inhibition of mild steel in $\mathrm{H}_{3} \mathrm{PO}_{4}$ solution. In this work, a triazole derivative containing nitrogen, sulphur, and aromatic ring was synthesized and had been studied on the corrosion inhibition of mild steel in $\mathrm{H}_{3} \mathrm{PO}_{4}$ solutions by weight loss and potentiodynamic polarization methods.

\section{Experimental Method}

2.1. Materials. Figure 1 shows the molecular structure of the investigated compound, which has been labelled PAMT.

The synthesis and characterization (spectral measurements) of the PAMT was as described and documented elsewhere previously [21].

The chemical composition wt $\%$ of mild steel was as shown in Table 1.

The specimens for the gravimetric determination were cut from steel sheet and measured approximately $4 \mathrm{~cm} \times$ $1 \mathrm{~cm} \times 0.05 \mathrm{~cm}$. The working electrode (WE) for the potentiodynamic tests was cut from steel plate $\left(1.0 \mathrm{~cm}^{2}\right)$ and was embedded in chemical resistant epoxy resin. A platinum foil was used as the auxiliary electrode and the reference electrode was a saturated calomel electrode (SCE) coupled to a Luggin capillary whose tip was located between the working electrode and the auxiliary electrode. All solutions were prepared from bidistilled water and $\mathrm{AR}$ grade $\mathrm{H}_{3} \mathrm{PO}_{4}$ was used.

2.2. Procedures. The specimens were successively abraded with a series of $\mathrm{SiC}$ paper to a final finish using 1500 grade paper. They were then degreased in acetone, washed with bidistilled water, washed in acetone, dried, weighed, and immersed in the test solution $(100 \mathrm{~mL})$ for $120 \mathrm{~min}$ in air without bubbling. At the conclusion of a run the specimens were washed with bidistilled water and acetone, dried, and immediately weighed. The tests were then repeated at different temperature.

The working electrode was immersed in the test solution at natural potential for 40 minutes before measurement until a steady state appeared. To obtain the Tafel slopes, polarization curves were performed by polarizing to $\pm 250 \mathrm{mv}$ with respect to the free corrosion potential $\left(E_{\text {corr }}\right)$ at a scan rate of $0.5 \mathrm{mV} / \mathrm{s}$. All the potentiodynamic measurements were performed by PARSTAT 2263 Potentiostat/Galvanostat

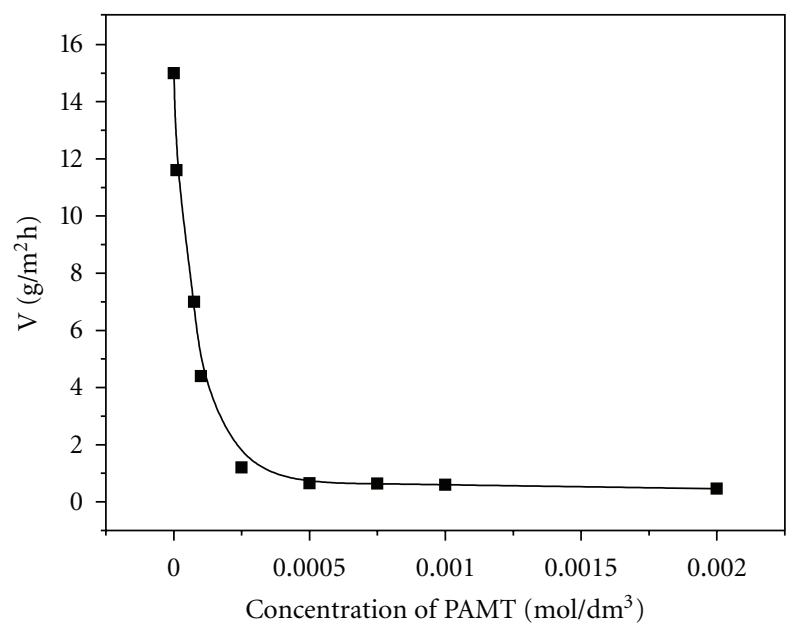

FIGURE 2: Variation of corrosion rate of mild steel with concentration of PAMT in $2 \mathrm{~mol} / \mathrm{dm}^{3} \mathrm{H}_{3} \mathrm{PO}_{4}\left(30^{\circ} \mathrm{C}\right)$.

(Princeton Applied Research). All runs were done at $30^{\circ} \mathrm{C}$ in air atmosphere without bubbling.

\section{Results and Discussion}

3.1. Weight Loss Tests and Adsorption Isotherm. A measure of the inhibition efficiency (IE) of PAMT in $2 \mathrm{~mol} / \mathrm{dm}^{3}$ $\mathrm{H}_{3} \mathrm{PO}_{4}$ at $30^{\circ} \mathrm{C}$ at different inhibitor concentration levels was ascertained by the weight loss method. In each case the specimens were exposed for a $2 \mathrm{hr}$ period. The inhibition efficiency is calculated as follows:

$$
\mathrm{IE} \%=\left[1-\frac{W_{i}}{W_{u}}\right] \times 100,
$$

where $W_{i}$ and $W_{u}$ are the weight losses per unit area per unit time in the presence and absence of the inhibitor, respectively. Figure 2 gives the corrosion rate values of mild steel in $2 \mathrm{~mol} / \mathrm{dm}^{3} \mathrm{H}_{3} \mathrm{PO}_{4}$ solution at different concentrations of PAMT. It is clear that the corrosion rates of the steel gradually decrease as the concentration of PAMT increases. Figure 3 shows the variation of inhibition efficiency with the concentration of the inhibitor. As shown, the inhibition efficiency increases with the increase of inhibitor concentration. The maximum inhibition efficiency is approximately $97 \%$. This behavior could be attributed to the increase of the surface area covered by the adsorbed molecules of PAMT with the increase of its concentration.

The interaction of inhibitor with the surface of metal can be described by physical (electrostatic) adsorption, by chemisorptions, or by complexation that are influenced by the nature and charge of the metal, the chemical structure of the inhibitor, and the type of electrolyte. Adherence to the Langmuir adsorption isotherm is generally regarded to indicate chemisorptions, and this was tested for by Langmuir adsorption isotherm [22, 23]:

$$
\theta=\frac{K C}{(1+K C)},
$$




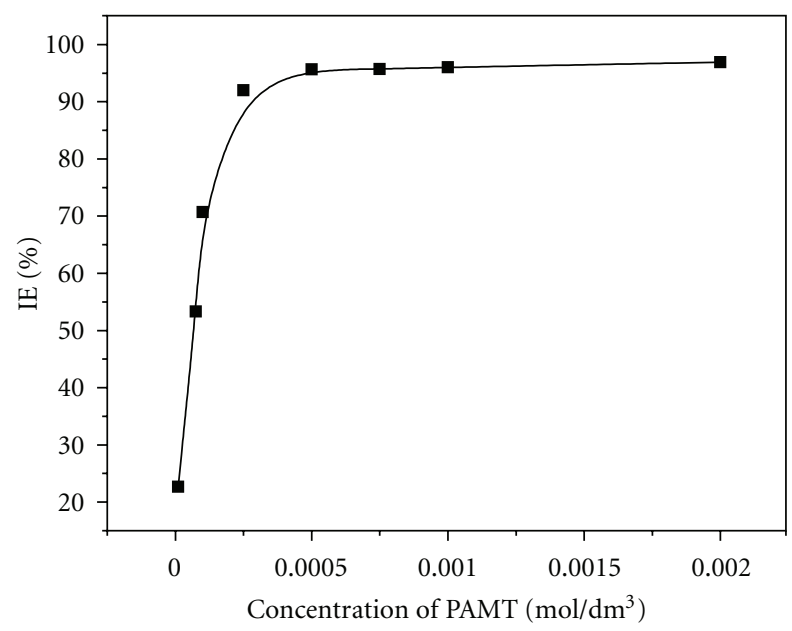

FIGURE 3: Variation of IE of mild steel in $2 \mathrm{~mol} / \mathrm{dm}^{3} \mathrm{H}_{3} \mathrm{PO}_{4}\left(30^{\circ} \mathrm{C}\right)$ with concentration of the inhibitor.

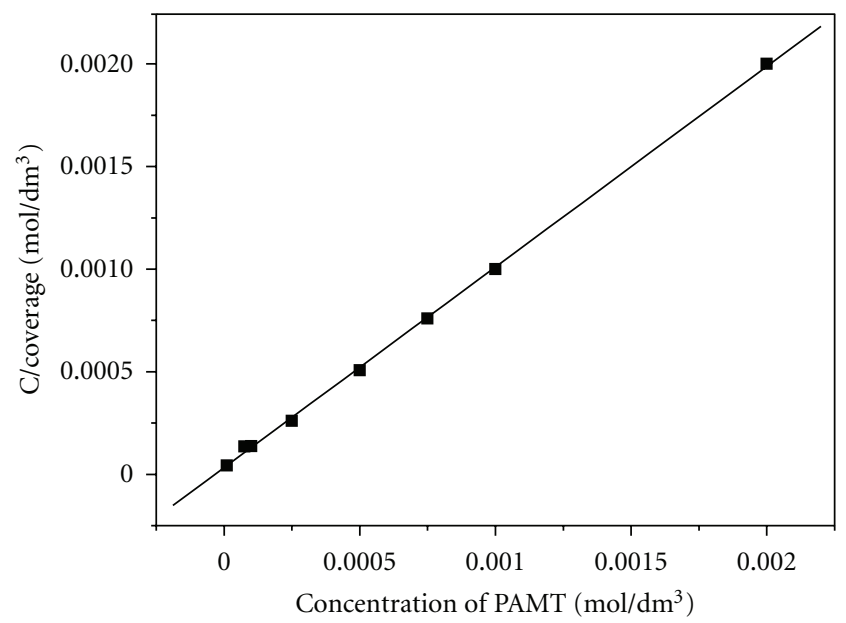

Figure 4: Dependence of $C /$ coverage $(C / \theta)$ on concentration of PAMT in the presence of $2 \mathrm{~mol} / \mathrm{dm}^{3} \mathrm{H}_{3} \mathrm{PO}_{4}$ at $30^{\circ} \mathrm{C}$.

equation (2) can be rearranged to:

$$
\frac{C}{\theta}=C+\frac{1}{K},
$$

where $K$ is the constant of adsorption, $C$ is the inhibitor concentration, and $\theta$ is the degree of surface coverage for different concentrations of the inhibitor. Here $\theta$ can be written as [24]:

$$
\theta=\frac{\left(r_{0}-r\right)}{\left(r_{0}-r_{m}\right)}
$$

where $r_{0}$ is the corrosion rate of the specimens without the inhibitor and $r_{m}$ is the smallest corrosion rate in the presence of the inhibitor.

Figure 4 shows the relation between $C / \theta$ and $C$ at $30^{\circ} \mathrm{C}$. A straight-line relationship with a slope of unity is observed and the linear correlation coefficient is 0.9997 . This behavior suggests that the adsorption of PAMT onto metal surface obeys the Langmuir adsorption isotherm. The value of $K$ for

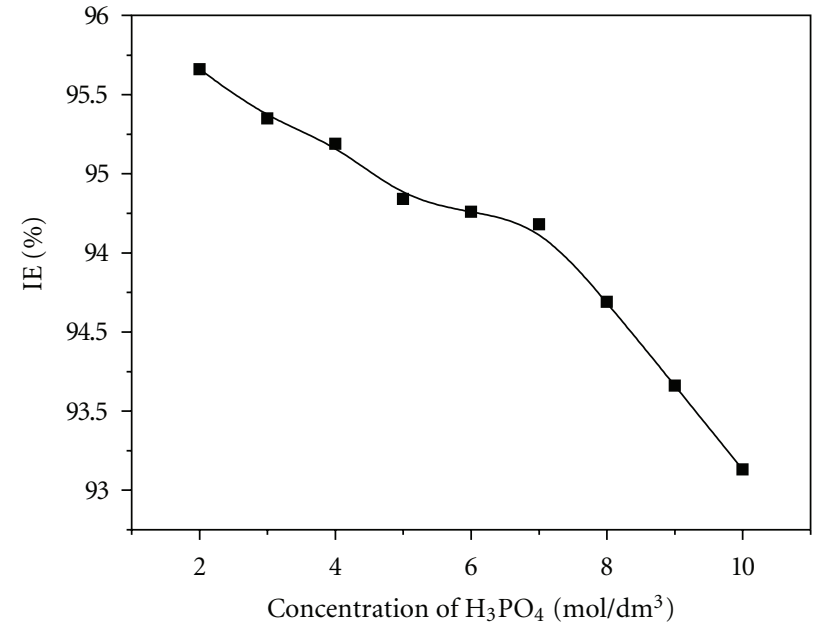

Figure 5: Effect of change in $\mathrm{H}_{3} \mathrm{PO}_{4}$ concentration $\left(30^{\circ} \mathrm{C}\right)$ on IE of the inhibitor at $5 \times 10^{-4} \mathrm{~mol} / \mathrm{dm}^{3}$ level for the mild steel.

PAMT on mild steel in $2 \mathrm{~mol} / \mathrm{dm}^{3} \mathrm{H}_{3} \mathrm{PO}_{4}$ at $30^{\circ} \mathrm{C}$ can be determined from the intercept of Figure $4: K=3.04 \times 10^{4}$ $\left(\mathrm{dm}^{3} / \mathrm{mol}\right)$. The standard free energy of adsorption $\left(\Delta G_{\text {ads }}^{o}\right)$ can be obtained according to the following [25]:

$$
K=\left(\frac{1}{55.5}\right) \exp \left(\frac{-\Delta G_{\mathrm{ads}}^{o}}{R T}\right)
$$

where $T$ is the absolute temperature and $R$ is the universal gas constant. The 55.5 is the concentration of water in solution expressed in molar concentration. The value of $\Delta G_{\text {ads }}^{o}$ for PAMT as calculated from (5) in $2 \mathrm{~mol} / \mathrm{dm}^{3} \mathrm{H}_{3} \mathrm{PO}_{4}$ at $30^{\circ} \mathrm{C}$ was $-36.12 \mathrm{~kJ} \mathrm{~mol}^{-1}$. The higher value of $K$ and the negative value of $\Delta G_{\text {ads }}^{o}$ indicate spontaneous adsorption of the inhibitor and are characteristics of a strong interaction with the metal surface [26]. The obtained $\Delta G_{\text {ads }}^{o}$ value points out that PAMT is strongly adsorbed on the metal surface. Generally the values of $\Delta G_{\text {ads }}^{o}$ above $-40 \mathrm{~kJ} \mathrm{~mol}^{-1}$ are consistent with chemisorption, whilst those below $-20 \mathrm{~kJ} \mathrm{~mol}^{-1}$ involve electrostatic interaction $[27,28]$. The value of $\Delta G_{\text {ads }}^{o}$ indicates that the adsorption of PAMT is predominantly by chemisorption.

3.2. The Effect of Acid Concentration and Temperature on Inhibition. Figure 5 shows the effect of changing $\mathrm{H}_{3} \mathrm{PO}_{4}$ concentration at $30^{\circ} \mathrm{C}$ on the inhibitor efficiency of PAMT at the $5 \times 10^{-4} \mathrm{~mol} / \mathrm{dm}^{3}$ level. Although the inhibitor efficiency decreases slowly with increasing $\mathrm{H}_{3} \mathrm{PO}_{4}$ concentration, for $7 \mathrm{~mol} / \mathrm{dm}^{3}$ acid level (corresponding to the concentration of $\mathrm{H}_{3} \mathrm{PO}_{4}$ produced by the dihydrate wet-method industrial process) the inhibition efficiency still reached to approximately $94.7 \%$. At the $9 \mathrm{~mol} / \mathrm{dm}^{3}$ acid level (approximately that reached in the hemihydrate wet-method process) the inhibition efficiency was $94 \%$.

Mathur and Vasudevan plotted the logarithm of the corrosion rate of iron against the molar concentration of $\mathrm{H}_{3} \mathrm{PO}_{4}$ and obtained a straight line relationship [29]. The 


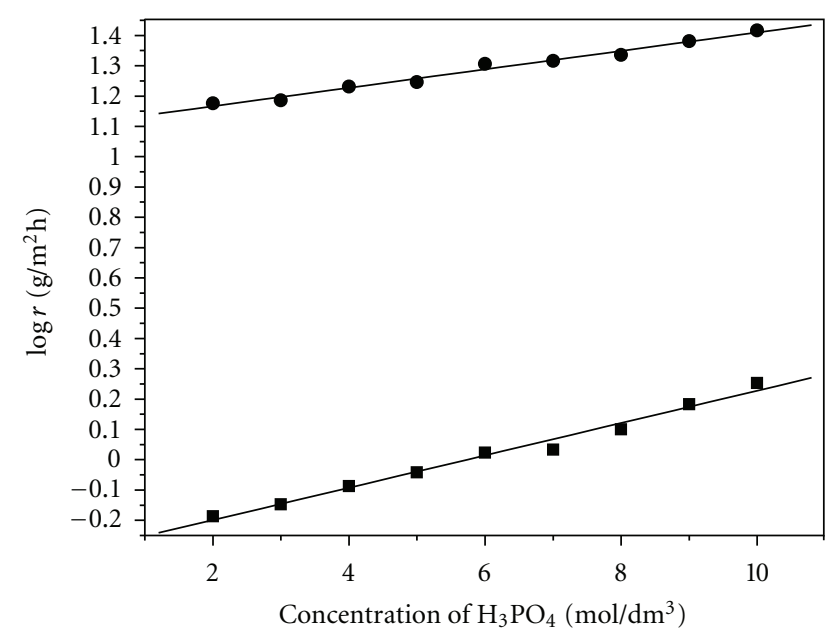

FIGURE 6: Variation of $\log r$ with concentration of $\mathrm{H}_{3} \mathrm{PO}_{4}$ for mild steel at $30^{\circ} \mathrm{C}$ : (a) (—- - blank; (b) (———) $5 \times 10^{-4} \mathrm{~mol} / \mathrm{dm}^{3}$ PMAT.

following rate equation was set up to describe the straight line relationship:

$$
\log r=\log k+B C,
$$

where $k$ is the specific reaction rate constant, $B$ is a constant for the reaction, and $C$ is the molar concentration of acid. Replacing $k$ with $A \mathrm{e}^{-E / R T}$ and expanding gives

$$
\log r=\left(\log A+\frac{B C}{2.303}\right)-\frac{E}{2.303 R T},
$$

where $E$ is the apparent activation energy, $A$ is the frequency factor and $R=8.314 \mathrm{~J} \mathrm{~K}^{-1} \mathrm{~mol}^{-1}$. Both $k$ and $B$ may be obtained from the plot of $\log r$ against $C$, whilst $E$ and $A$ are calculated from a plot of $\log r$ against $1 / T$.

In the present study of corrosion of mild steel in phosphoric acid solutions with and without the inhibitor straight line relationships were obtained. Equations (6) and (7) are shown graphically in Figures 6 and 7, respectively.

In the presence of PAMT, the magnitude of $r$ is suppressed as is its tendency to increase with the acidic concentration. Calculated kinetic parameters are listed in Table 2. The values of $k$ in (6) were obtained by extrapolation of the straight line in Figure 5. $k$ can be regarded as a "commencing rate" at zero acid concentration and the superiority of PAMT as an inhibitor is clearly apparent by comparing values of $k$ between the blank and in the presence of PAMT. The calculated values of $E$ (for $\mathrm{H}_{3} \mathrm{PO}_{4}$ at the $2 \mathrm{~mol} / \mathrm{dm}^{3}$ level) are also shown in Table 2. The value of the apparent activation energy in absence of inhibitor is $42.59 \mathrm{~mol} / \mathrm{dm}^{3}$. The value is also of the order of the activation energies encountered for the hydrogen evolution reaction [30]. This is in accordance with the fact that the hydrogen evolution reaction in absence of an inhibitor is the rate determining step for the corrosion reaction. Compared with the value of the apparent activation energy in the presence of $5 \times$ $10^{-4} \mathrm{~mol} / \mathrm{dm}^{3}$ PMAT, the difference is not considered to be significant. The presence of PAMT adsorbed on the metal

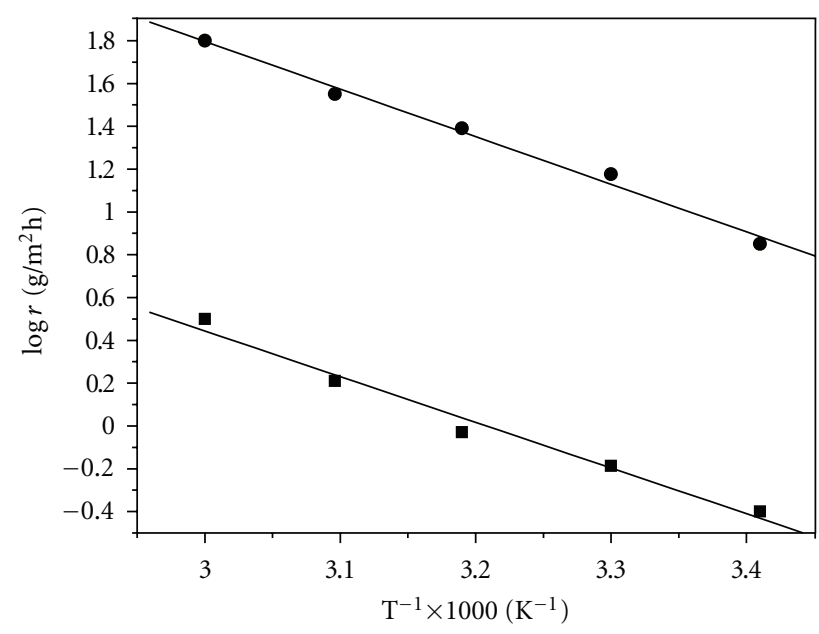

FIgURE 7: Variation of $\log r$ with $1 / T$ in the absence and presence of inhibitor: (a) —- blank; (b) $-\square-5 \times 10^{-4} \mathrm{~mol} / \mathrm{dm}^{3}$ PAMT.

does not act to change significantly the energy barrier for the corrosion reaction. PAMT does not change the mechanism of the rate-determining step of the corrosion process, although it significantly reduces the rate [31]. This result agrees with that reported previously $[32,33]$. The frequency factor in the presence of the inhibitor is also not significantly changed.

3.3. Polarization Measurements. Anodic and cathodic polarization curves for electrodes in $2 \mathrm{~mol} / \mathrm{dm}^{3}$ phosphoric acid in the absence and presence of various concentrations of inhibitor are shown in Figure 8. The electrochemical parameters such as corrosion potential $\left(E_{\text {corr }}\right)$, corrosion current density $\left(i_{\text {corr }}\right)$, and Tafel slopes $\left(\beta_{a}, \beta_{c}\right)$ are calculated by using Tafel fit and listed in Table 3.

The inhibition efficiency was calculated from the following:

$$
\operatorname{IE}(\%)=100 \times \frac{\left(i_{\text {corr }}^{o}-i_{\text {corr }}\right)}{i_{\text {corr }}^{o}},
$$

where $i_{\text {corr }}^{o}$ and $i_{\text {corr }}$ are the corrosion current densities in the absence and presence of the inhibitor, respectively.

It is seen that PAMT shifts both the cathodic and anodic branches of the polarization curves of the pure acid solution to lower values of current density indicating the inhibition of both the hydrogen evolution (HER) and mild steel dissolution reactions. Some retardation of the anodic reaction is observed but cathodic polarization is clearly dominant. PAMT inhibited the hydrogen evolution more than anodic dissolution of mild steel. The corrosion potential is almost unchanged. These observations indicate that a mixed-type control and PAMT is an inhibitor of mixedtype with predominant effect on the cathodic reaction for the corrosion of mild steel in $2 \mathrm{~mol} / \mathrm{dm}^{3} \mathrm{H}_{3} \mathrm{PO}_{4}$. It can also be seen that PAMT decreases the corrosion current densities at all the studied concentrations, meaning that the corrosion rate of steel is reduced significantly. The inhibition efficiency obtained from polarization measurement is in 
TABLE 2: Calculated values of kinetic parameters for the corrosion of mild steel in $\mathrm{H}_{3} \mathrm{PO}_{4}$ containing PAMT.

\begin{tabular}{|c|c|c|c|c|}
\hline Inhibitor concentration & $k\left(\mathrm{~g} \mathrm{~m}^{-2} \mathrm{~h}^{-1}\right)$ & $B\left(\mathrm{~g} \mathrm{~m}^{-2} \mathrm{~h}^{-1} \mathrm{~mol}^{-1} \mathrm{dm}^{3}\right)$ & $A\left(\mathrm{r}^{-1}\right)$ & $E\left(\mathrm{~kJ} \mathrm{~mol}^{-1}\right)$ \\
\hline None & 12.76 & 0.03042 & $2.52 \times 10^{10}$ & 42.59 \\
\hline PAMT & & & & \\
\hline$\left(5 \times 10^{-4} \mathrm{~mol} / \mathrm{dm}^{3}\right)$ & 0.4948 & 0.05332 & $5.03 \times 10^{8}$ & 40.87 \\
\hline
\end{tabular}

TABLE 3: Electrochemical parameters obtained from polarization measurements at $30^{\circ} \mathrm{C}$.

\begin{tabular}{lcccc}
\hline PAMT $\left(\mathrm{mol} / \mathrm{dm}^{3}\right)$ & $E_{\text {corr }}(\mathrm{mV}$ versus SCE $)$ & $i_{\text {corr }}\left(\mu \mathrm{A} \mathrm{cm}^{-2}\right)$ & $\beta_{c}(\mathrm{mV} \mathrm{dec}-1)$ & $\beta_{a}\left(\mathrm{mV} \mathrm{dec}^{-1}\right)$ \\
\hline None & -473.7 & 648.6 & 136.9 & 47.97 \\
$1.0 \times 10^{-3}$ & -472.8 & 14.37 & 104.3 & 23.00 \\
$1.0 \times 10^{-4}$ & -470.2 & 212.7 & 106.3 & 97.8 \\
$7.5 \times 10^{-5}$ & -481.6 & 276.9 & 120.4 & 67.2 \\
\hline
\end{tabular}

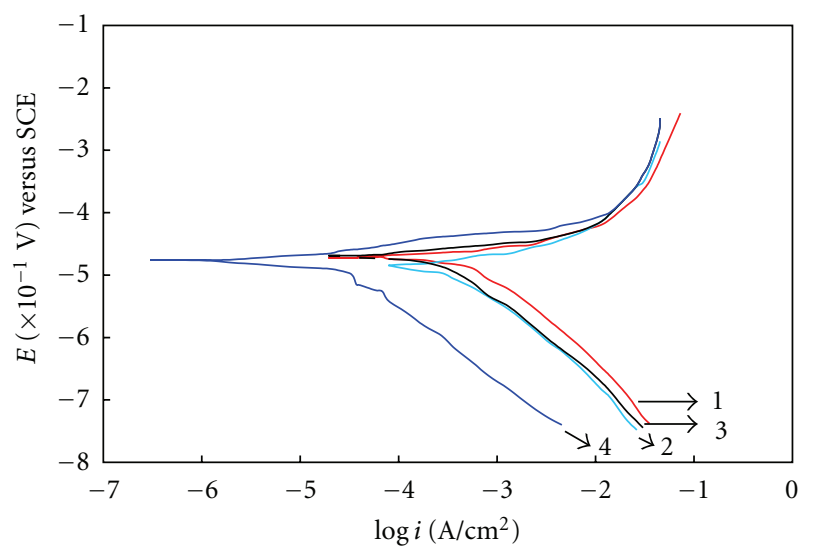

Figure 8: Polarization curves for mild steel in $2 \mathrm{M} \mathrm{H}_{3} \mathrm{PO}_{4}$ at $30^{\circ} \mathrm{C}$ : (1) blank; (2) $7.5 \times 10^{-5} \mathrm{~mol} / \mathrm{dm}^{3}$ PAMT; (3) $1 \times 10^{-4} \mathrm{~mol} / \mathrm{dm}^{3}$ PAMT; (4) $1 \times 10^{-3} \mathrm{~mol} / \mathrm{dm}^{3}$ PAMT.

good agreement with results obtained from weight loss tests. Moreover, the anodic and cathodic Tafel slope values are different from the ones obtained with and without the presence of PAMT, respectively, suggesting that the mechanism of the reaction of mild steel in $2 \mathrm{~mol} / \mathrm{dm}^{3} \mathrm{H}_{3} \mathrm{PO}_{4}$ is influenced by the presence of PAMT.

The adsorption PAMT on the metal surface can occur on the basis of donor-acceptor interactions between the $\pi$ electrons of the heterocycle compound and the lone pairs of the heteroatoms and vacant d-orbitals of iron surface atoms [34]. The presence of mercapto substituent in the organic structures makes the formation of $\mathrm{d} \pi-\mathrm{d} \pi$ bond resulting from overlap of $3 \mathrm{~d}$ electrons from $\mathrm{Fe}$ atom to the $3 \mathrm{~d}$ vacant orbital of the sulphur atom possible [35], which enhances the adsorption of the compounds on the metal surface. When PAMT is dissolved in $\mathrm{H}_{3} \mathrm{PO}_{4}$ medium, protonation can occur by the reaction of amino group with $\mathrm{H}_{3} \mathrm{PO}_{4}$. Amines and heterocycle nitrogen compounds may also adsorb through electrostatic interactions between the positively charged nitrogen atom and negatively charged metal surface. The protonated compounds may decrease the hydrogen evolution by adsorbing on the cathodic sites of the mild steel. The adsorption of amine can be influenced by the nature of anions in acidic solution [6]. Being specifically adsorbed, they create an excess negative charge towards the solution and favour more adsorption of the cations [7]. PAMT may adsorb anodic sites through nitrogen and sulphur atoms and aromatic and heterocyclic rings which are electron donating groups and decrease anodic dissolution of mild steel.

\section{Conclusion}

(1) The corrosion rates of the steel gradually decrease as the concentration of PAMT increases. The inhibition efficiency increases with the increase of inhibitor concentration and the maximum inhibition efficiency is approximately $97 \%$ in $2 \mathrm{~mol} / \mathrm{dm}^{3} \mathrm{H}_{3} \mathrm{PO}_{4}$.

(2) PAMT also shows good corrosion inhibition at higher $\mathrm{H}_{3} \mathrm{PO}_{4}$ concentrations corresponding to the concentrations of $\mathrm{H}_{3} \mathrm{PO}_{4}$ produced by the dihydrate or hemihydrate wet methods industrial process. The inhibition efficiencies still reach to approximately $94.7 \%$ and $94 \%$, respectively.

(3) The adsorption of PAMT on the mild steel surface in $2 \mathrm{~mol} / \mathrm{dm}^{3} \mathrm{H}_{3} \mathrm{PO}_{4}$ medium obeys a Langmuir adsorption isotherm. The negative value of $\Delta G_{\text {ads }}^{o}$ obtained from the study indicates that PAMT was strongly adsorbed on the steel surface and predominantly by chemisorption.

(4) PAMT acts as a mixed-type inhibitor retarding the anodic and cathodic corrosion reactions with predominant effect on the cathodic reaction.

\section{References}

[1] G. Trabanelli, "Inhibitors - an old remedy for a new challenge," Corrosion, vol. 47, no. 6, pp. 410-419, 1991.

[2] S. E. Nataraja, T. V. Venkatesha, K. Manjunatha, B. Poojary, M. K. Pavithra, and H. C. Tandon, "Inhibition of the corrosion of steel in hydrochloric acid solution by some organic molecules containing the methylthiophenyl moiety," Corrosion Science, vol. 53, no. 8, pp. 2651-2659, 2011.

[3] X. Li, S. Deng, and H. Fu, "Inhibition by tetradecylpyridinium bromide of the corrosion of aluminium in hydrochloric acid 
solution," Corrosion Science, vol. 53, no. 4, pp. 1529-1536, 2011.

[4] N. Caliskan and E. Akbas, "The inhibition effect of some pyrimidine derivatives on austenitic stainless steel in acidic media," Materials Chemistry and Physics, vol. 126, no. 3, pp. 983-988, 2011.

[5] M. Z. A. Rafiquee, N. Saxena, S. Khan, and M. A. Quraishi, "Influence of surfactants on the corrosion inhibition behaviour of 2-aminophenyl-5-mercapto-1-oxa-3,4-diazole (AMOD) on mild steel," Materials Chemistry and Physics, vol. 107, no. 2-3, pp. 528-533, 2008.

[6] C. Fiaud, A. Harch, D. Mallouh, and M. Tzinmann, "The inhibition of iron corrosion by acetylenic alcohols in acid solutions at high temperature," Corrosion Science, vol. 35, no. 5-8, pp. 1437-1444, 1993.

[7] B. Mernari, H. ElAttari, M. Traisnel, F. Bentiss, and M. Lagrenee, "3,5-Bis(n-pyridyl)-4-amino-1,2,4-triazoles on the corrosion for mild steel in $1 \mathrm{M} \mathrm{HCl}$ medium," Corrosion Science, vol. 40, pp. 391-399, 1998.

[8] W. Qafsaoui and H. Takenouti, "Corrosion protection of 2024T3 aluminium alloy by electro-polymerized 3-amino 1,2,4triazole in sulphate solution containing chloride," Corrosion Science, vol. 52, no. 11, pp. 3667-3676, 2010.

[9] M. Finšgar and I. Milošev, "Inhibition of copper corrosion by 1,2,3-benzotriazole: a review," Corrosion Science, vol. 52, no. 9, pp. 2737-2749, 2010.

[10] M. L. Zheludkevich, K. A. Yasakau, S. K. Poznyak, and M. G. S. Ferreira, "Triazole and thiazole derivatives as corrosion inhibitors for AA2024 aluminium alloy," Corrosion Science, vol. 47, no. 12, pp. 3368-3383, 2005.

[11] F. Bentiss, M. Traisnel, L. Gengembre, and M. Lagrenée, "Inhibition of acidic corrosion of mild steel by 3,5-diphenyl4H-1,2,4-triazole," Applied Surface Science, vol. 161, no. 1, pp. 194-202, 2000.

[12] D. Gopi, K. M. Govindaraju, V. Collins Arun Prakash, D. M. Angeline Sakila, and L. Kavitha, "A study on new benzotriazole derivatives as inhibitors on copper corrosion in ground water," Corrosion Science, vol. 51, no. 10, pp. 2259-2265, 2009.

[13] L. Wang, "Inhibition of mild steel corrosion in phosphoric acid solution by triazole derivatives," Corrosion Science, vol. 48, no. 3, pp. 608-616, 2006.

[14] M. A. Quraishi and D. Jamal, "Corrosion inhibition of N80 steel and mild steel in 15\% boiling hydrochloric acid by a triazole compound-SAHMT," Materials Chemistry and Physics, vol. 68, no. 1-3, pp. 283-287, 2001.

[15] S. Zhang, Z. Tao, S. Liao, and F. Wu, "Substitutional adsorption isotherms and corrosion inhibitive properties of some oxadiazol-triazole derivative in acidic solution," Corrosion Science, vol. 52, no. 9, pp. 3126-3132, 2010.

[16] A. S. Fouda and A. S. Ellithy, "Inhibition effect of 4phenylthiazole derivatives on corrosion of $304 \mathrm{~L}$ stainless steel in $\mathrm{HCl}$ solution," Corrosion Science, vol. 51, no. 4, pp. 868-875, 2009.

[17] H. L. Wang, R. B. Liu, and J. Xin, "Inhibiting effects of some mercapto-triazole derivatives on the corrosion of mild steel in 1.0 M HC1 medium," Corrosion Science, vol. 46, no. 10, pp. 2455-2466, 2004.

[18] F. Bentiss, M. Lagrenee, M. Traisnel, and J. C. Hornez, "The corrosion inhibition of mild steel in acidic media by a new triazole derivative," Corrosion Science, vol. 41, no. 4, pp. 789803, 1999.

[19] L. Wang, G. Y. Yin, Q. F. Zhang, and J. X. Pu, "Corrosion inhibition of low-carbon steel in phosphoric acid solution by 2-mercaptobeneoxazole," Corrosion Science, vol. 56, pp. 10831085, 2000.

[20] Y. Jianguo, W. Lin, V. Otieno-Alego, and D. P. Schweinsberg, "Polyvinylpyrrolidone and polyethylenimine as inhibitors for the corrosion of a low carbon steel in phosphoric acid," Corrosion Science, vol. 37, no. 6, pp. 975-985, 1995.

[21] Z. Y. Zhang, M. Li, and N. Zhao, "Synthesis of 3alkyl/aryl-6-(3'pyridyl)-s-triazole[3,4-b]-1,3,4-thiadiazoles ," Organic Chemistry, vol. 13, no. 4, pp. 397-402, 1993.

[22] G. N. Mu, T. P. Zhao, M. Liu, and T. Gu, "Effect of metallic cations on corrosion inhibition of an anionic surfactant for mild steel," Corrosion, vol. 52, no. 11, pp. 853-856, 1996.

[23] L. Yang, X. Li, and G. Mu, "Synergistic effect between 4-(2pyridylazo) resorcin and chloride ion on the corrosion of cold rolled steel in $1.0 \mathrm{M}$ phosphoric acid," Applied Surface Science, vol. 253, no. 5, pp. 2367-2372, 2006.

[24] I. Sekine and Y. Hirakawa, "Effect of 1-hydroxyethylidene-1, 1 -diphosphonic acid on the corrosion of SS 41 steel in $0.3 \%$ sodium chloride solution," Corrosion, vol. 42, no. 5, pp. 272277, 1986.

[25] E. Cano, J. L. Polo, A. L. A. Iglesia, and J. M. Bastidas, "A study on the adsorption of benzotriazole on copper in hydrochloric acid using the inflection point of the isotherm," Adsorption, vol. 10, no. 3, pp. 219-225, 2004.

[26] M. H. Wahdan, A. A. Hermas, and M. S. Morad, "Corrosion inhibition of carbon-steels by propargyltriphenylphosphonium bromide in H," Materials Chemistry and Physics, vol. 76, no. 2, pp. 111-118, 2002.

[27] K. F. Khaled, "Molecular simulation, quantum chemical calculations and electrochemical studies for inhibition of mild steel by triazoles," Electrochimica Acta, vol. 53, no. 9, pp. 34843492, 2008.

[28] F. Bentiss, M. Lebrini, and M. Lagrenée, “Thermodynamic characterization of metal dissolution and inhibitor adsorption processes in mild steel/2,5-bis(n-thienyl)-1,3,4-thiadiazoles/ hydrochloric acid system," Corrosion Science, vol. 47, no. 12, pp. 2915-2931, 2005.

[29] P. B. Mathur and T. Vasudevan, "Reaction rate studies for the corrosion of metal in acids-I, iron in mineral acids," Corrosion, vol. 38, pp. 171-178, 1982.

[30] B. F. Conway, Electrochemical Data, Elsevier, New York, NY, USA, 1952.

[31] R. R. Annand, R. M. Hurd, and N. Hackerman, "Adsorption of monomeric and polymeric amino corrosion inhibitiors on steel," Journal of The Electrochemical Society, vol. 112, pp. 138144, 1965.

[32] L. Wang, "Evaluation of 2-mercaptobenzimidazole as corrosion inhibitor for mild steel in phosphoric acid," Corrosion Science, vol. 43, no. 12, pp. 2281-2289, 2001.

[33] L. Wang, J. X. Pu, and H. C. Luo, "Corrosion inhibition of zinc in phosphoric acid solution by 2-mercaptobenzimidazole," Corrosion Science, vol. 45, no. 4, pp. 677-683, 2003.

[34] S. Muralidharan, M. A. Quraishi, and S. V. K. Iyer, "The effect of molecular structure on hydrogen permeation and the corrosion inhibition of mild steel in acidic solutions," Corrosion Science, vol. 37, no. 11, pp. 1739-1750, 1995.

[35] B. Bonnelly, T. C. Dowine, R. Grzekowiak, H. R. Hamburg, and D. Short, "The effect of electronic delocalization in organic groups $\mathrm{R}$ in substituted thiocarbamoryl R-CS- $\mathrm{NH}_{2}$ and related compoynds on inhibition efficiency," Corrosion Science, vol. 18, pp. 109-116, 1978. 

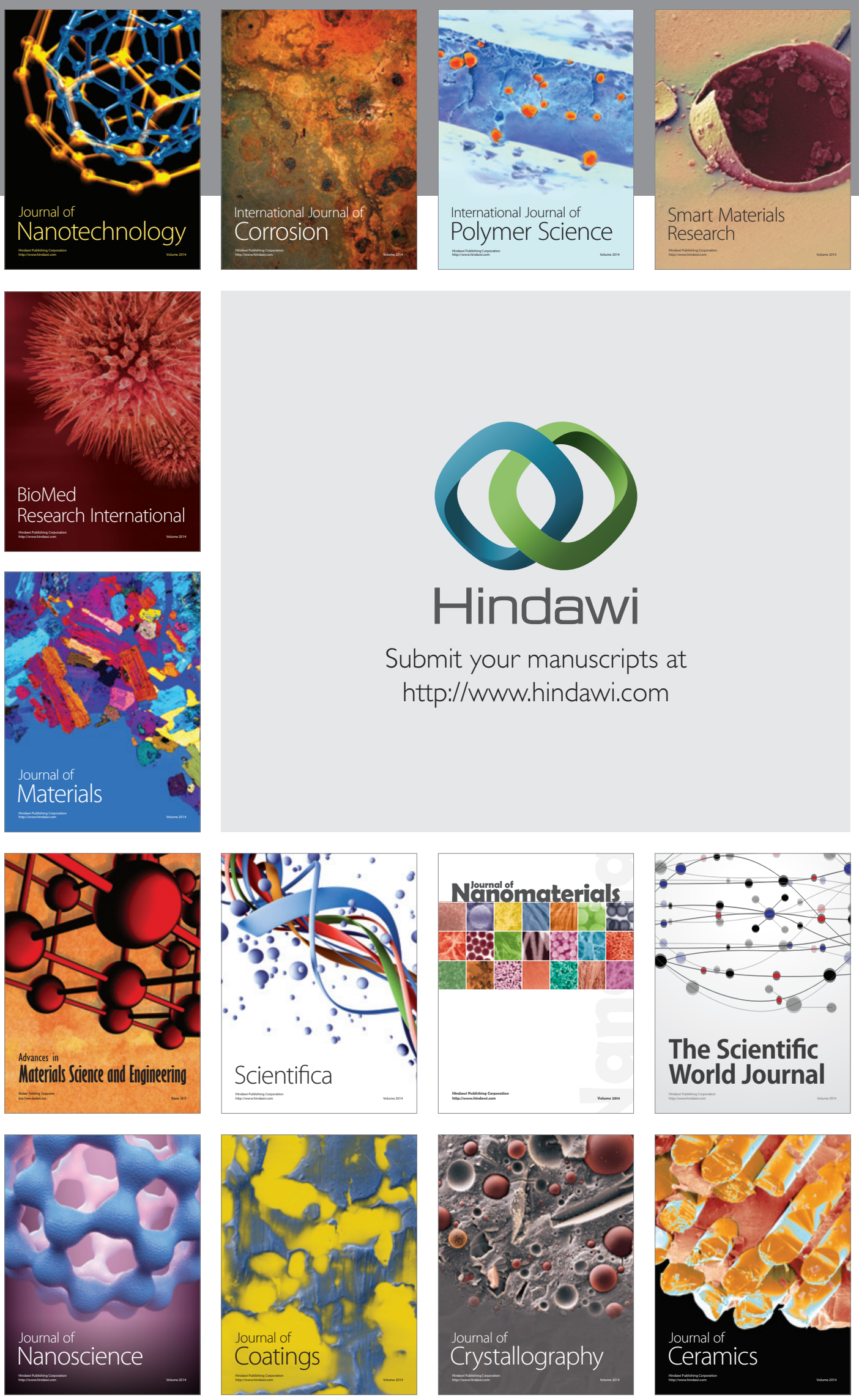

The Scientific World Journal

Submit your manuscripts at

http://www.hindawi.com

\section{World Journal}

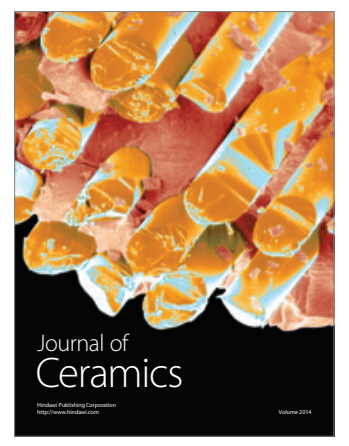

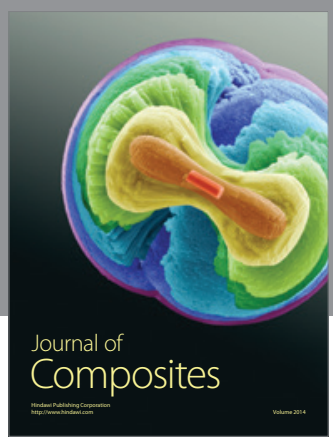
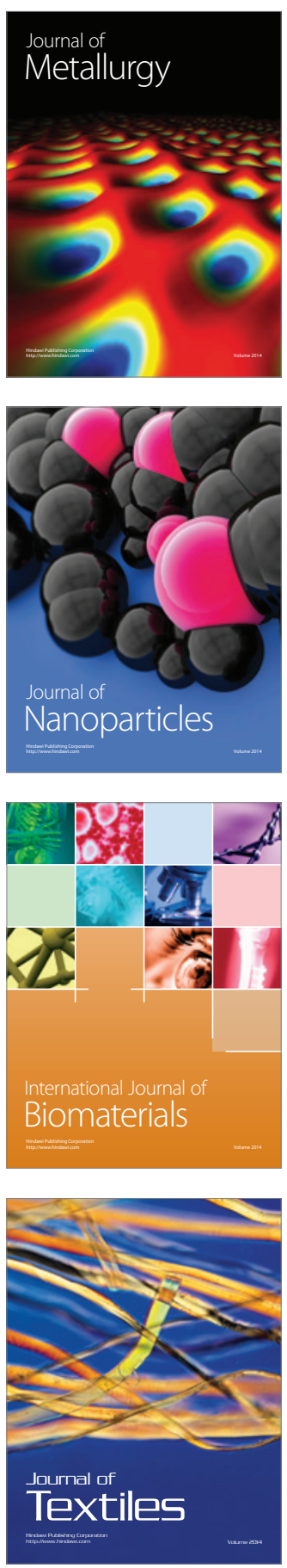